\title{
Chapter 2 \\ Millennium Alliance for Humanity and the Biosphere (MAHB): Integrating Social Science and the Humanities into Solving Sustainability Challenges
}

\author{
Ilan Kelman, Eugene A. Rosa, Tom R. Burns, Paul Ehrlich, \\ Joan M. Diamond, Nora Machado, Donald Kennedy, and Lennart Olsson
}

\subsection{Introduction}

\subsubsection{Dealing with Scientific Silos and Uncertainties}

Comprehensive assessments have shown the wide variety of severe environmental problems facing and caused by humanity (e.g. Ehrlich and Ehrlich 2013; IPCC (Intergovernmental Panel on Climate Change) 2007; MEA (Millennium Ecosystem Assessment) 2005; Mitchell et al. 2006). These problems result largely from the activities of a human population whose consumptive patterns have already exceeded the long-term capacity of the Earth to support that population (Rees 2006, 2013).

In memory of Gene Rosa who passed away in February 2013.

I. Kelman $(\bowtie)$

Institute for Risk \& Disaster Reduction (IRDR) and Institute for Global Health (IGH),

University College London (UCL), Gower Street, London WC1E 6BT, UK

e-mail: ilan_kelman@hotmail.com

E.A. Rosa

510 East C Street, Moscow, ID 83843, USA

T.R. Burns

Department of Sociology, University of Uppsala, Box 624, 75126 Uppsala, Sweden

P. Ehrlich

Department of Biological Sciences, Stanford University, Stanford, CA 94305-5020, USA

J.M. Diamond

Nautilus Institute for Security and Sustainability,

Shattuck Ave. \#300, Berkeley, CA 94710, USA

N. Machado

Center for Research and Studies in Sociology, Lisbon University Institute,

Avenida Forças Armadas, 1649-026 Lisbon, Portugal 
The problems fit a general pattern of diminishing marginal returns (Klare 2012) that Tainter (1988) saw as indicative of the coming collapse of complex societies. Despite the physical science knowledge establishing the current, threatened state of the Earth, concerted action on this knowledge is lacking.

Irrespective of the lack of substantive, concerted action, many examples exist of improvements. One instance has been policies and pressures to reduce the use of leaded gasoline to cut the amount of lead contamination in our bodies. Thomas et al. (1999) conducted a meta-analysis of nineteen studies on blood lead levels across all six inhabited continents. Seventeen of the studies measure blood lead levels before and after major reductions in the use of leaded gasoline. The remaining two studies surveyed populations with limited exposure to gasoline. They conclude that reducing lead in gasoline reduces the amount of lead in people's bodies.

Another example of an environmental improvement relates to acid rain. Acid rain refers to emissions of sulfur and nitrogen compounds, such as from coal-fired electricity generation plants, reducing the $\mathrm{pH}$ of rain. When acidic rain falls, it harms ecosystems such as by reducing the $\mathrm{pH}$ of soils and lakes, among other effects. Legislation to limit sulfur and nitrogen emissions in places such as North America and Europe reduced acid rain, permitting the ecosystems to recover (e.g. Reis et al. 2012).

Nevertheless, at least two overarching sustainability challenges remain. First, new environmental problems have emerged. For instance, recent research on endocrine-disrupting chemicals has highlighted humanity's ignorance of both their direct effects on human and environmental health and the myriad of potential synergisms among these toxins (Vandenberg et al. 2012). Another poignant example concerns negative, unintended consequences of the otherwise major achievement of The Montreal Protocol on Substances that Deplete the Ozone Layer from 1987. This protocol phased out the production and use of a list of chemicals which, when vented into the atmosphere, depleted the stratospheric ozone layer. Many were also greenhouse gases. Ironically, the substitutes for the ozone-depleting chemicals are also significant greenhouse gases, although it is hard to determine which chemicals are worse because complete life cycle analyses are needed (Velders et al. 2009). A "solution" to one environmental problem can cause or exacerbate other ones.

The second overarching sustainability challenge is that major differences in environmental conditions are evident based on location. For example, the UK has significantly reduced urban air pollution leading to an improvement in human health (Seaton et al. 1995) in contrast to Beijing where air pollution and associated human health impacts are staggering (Zhang et al. 2007). Acid rain also continues to be a major problem in China (Zhang et al. 2012), compared to the improvements in Europe and the USA mentioned above. Similarly, forestry regulation for multiple

\author{
D. Kennedy \\ The Center for Environmental Science and Policy (CESP), Stanford University, \\ Encina Hall E401, Stanford, CA 94305, USA \\ L. Olsson \\ Lund University Centre for Sustainability Studies (LUCSUS), Lund University, \\ P.O. Box 170, SE-221 00 Lund, Sweden
}


uses including logging is detailed and is enforced in Oregon leading to intensive management of forestry ecosystems (Boyle et al. 1997), compared to rampant unregulated and highly destructive deforestation in Papua New Guinea (Bryan et al. 2010).

These examples illustrate a remarkable contrast. The threats to humanity's future are often clear from the scientific evidence. Environment and sustainability problems can be solved and have been solved in some locations. Other locations do not apply the available knowledge for action while some new problems continue to emerge. Overall, the conclusion is that society has been unable or unwilling to take comprehensive steps to address the well-documented and continuing environmental and sustainability challenges, including with respect to resource management.

One difficulty in making sense of the scientific evidence and applying it for concerted action is the large degree of disciplinary silos. Plenty is published on, for instance, factors influencing pollutant transport to the Arctic (e.g. Downie and Fenge 2003; Eckhardt et al. 2003), but the work has varying levels of engagement with different disciplines and varying levels of resultant action from the knowledge. Sometimes, publications provide only a physical or chemical description without connection to any form of social science or policy. That is not inherently detrimental, since the physical science is a needed input and deserves publication in its own right. Nevertheless, much more than physical science is needed to understand society's interaction with resources and the environment-and how to inspire and formulate action addressing the problems identified.

Often, caught in their disciplinary silos, physical scientists will aim for full and comprehensive knowledge of a problem before being willing to recommend any form of action. Social science indicates that is not necessary, since techniques for decisionmaking under uncertainty exist alongside approaches for selecting action pathways which are likely to be beneficial over the long-term irrespective of the uncertainties and irrespective of what is not known. In fact, many positive examples exist of tackling sustainability problems without full physical science knowledge. These examples emerge from recent history, such as cleaning up Lake Erie and The Montreal Protocol on Substances that Deplete the Ozone Layer mentioned above.

Current initiatives exist as well. As a prominent example, little scientific doubt exists regarding observations about contemporary climate change and the human influences on it (IPCC 2007). Much work remains to be completed regarding, amongst other physical science challenges, feedback mechanisms from clouds (Dessler 2010) and the impact of climate change on tropical cyclones (Knutson et al. 2010). Supporting such physical science research would not only better understand the ultimate consequences of climate change, but would also highlight the importance of supporting curiosity-driven research with its unknown, and often spectacular, gains for humanity. While that research is ongoing, many communities are nonetheless taking action on their own, based on what is known, irrespective of the uncertainties and any knowledge limits.

Despite, or perhaps because of, any scientific uncertainties regarding climate change, Transition Towns (Barry and Quilley 2009) and relocalization movements (Kelman 2008) aim to transform entire cities toward pathways that are sustainable, irrespective of the climate pathway which emerges. Sector-specific approaches 
include "guerilla gardening" to use open space for food (Reynolds 2008) and community teams to reduce disaster vulnerability and to improve disaster response (Flint and Brennan 2006). These initiatives accept the physical science description of the problems, including the uncertainties and unknowns. They nevertheless aim to act on the basis of social sciences and humanities knowledge that exists, in order to help society to effect change irrespective of which pathway the climate pursues.

\subsubsection{Solving These Challenges}

Even with these polycentric examples, a significant need remains for a larger effort to fuse knowledge about physical and social systems into blueprints for action that are acceptable. Civilization needs to be "rescaled" to stabilize the population while reducing the average individual impact on the planet (Ehrlich et al. 2012). This means focusing on behavior and the reasons for behavior to understand better why we tend to ignore the high, destructive, and known human impact on the planet (Ehrlich et al. 2012). Humanity can no longer avoid dramatic change to society or the environment at global scales, but can potentially do a much better job of managing such change. Social science and humanities skills, interests, knowledge, and wisdom need to be mobilized and integrated into solving sustainability challenges, taking into consideration human behavior and values.

That does not need to come at the expense of tackling the many remaining fascinating scientific problems across the physical and social sciences. That does mean joining physical sciences, social sciences, humanities, and other fields to embrace as much knowledge as possible in order to break down the silos.

As one contribution towards that goal, this chapter highlights the importance of understanding and influencing human behavior: actions of individual and collective actors. The focus on human behavior, its causes, and mechanisms for influencing it is examined in the context of integrating physical sciences, social sciences, and the humanities to ensure that all available scientific knowledge contributes to action for sustainability.

To contribute to identifying the current status of integration, one initiative for doing so is presented: the Millennium Alliance for Humanity and the Biosphere (MAHB, pronounced "mob"). The next section defines and describes MAHB, including research and application. Then, a research agenda regarding resource management for and from MAHB is offered to pursue future opportunities for social science and humanities integration with physical sciences and policymaking. The key is not to await full knowledge and limited uncertainty before acting on any sustainability challenge. Instead, it is about using multiple disciplines in science to monitor and evaluate any measure implemented as an ongoing process, to ensure that actions do not exacerbate the existing problem or cause new problems. 


\subsection{Millennium Alliance for Humanity and the Biosphere (MAHB)}

\subsubsection{MAHB's Mission and Structure}

Extensive literature (e.g. Brown et al. 1987; Gatto 1995; Santillo 2007) compiles and critiques definitions of "sustainability" and "sustainable development". While recognizing the importance of definitional discussions, MAHB adopts a comparatively generic and succinct definition. Paraphrasing the Oxford English Dictionary, "sustainability" is societal processes (e.g. livelihoods and governance) that are maintained and continued without the long-term depletion of human or natural resources. Based on this definition, MAHB's mission is to foster, fuel, and inspire global conversations and actions to shift human cultures and institutions toward sustainable practices, through dealing with the drivers of environmental degradation, yielding an equitable and satisfying future.

These conversations and actions are conducted through three connected activities on human behavior for sustainability (Ehrlich and Kennedy 2005; Rosa et al. 2011):

1. Knowledge generation, i.e. producing new science.

MAHB facilitates and supports research which integrates physical sciences, technological knowledge, social sciences, and the humanities to better understand human sustainability-related behavior. One example of ongoing work is Ehrlich and Ehrlich's (2012) analysis going beyond the standard mantra that perpetual economic growth is the antithesis of sustainability in order to demonstrate how it is "biophysically impossible" (pp. 558-559; see also Bartlett 2004). For a sector-based approach, food is a theme with Jerneck and Olsson (2014) seeking to understand povertyagroforestry connections in Kenya so that the poorest people could have better opportunities to improve their situation without harming their land's sustainability.

As another example, in September 2012, MAHB opened the Institute of Foresight Intelligence at the Center for the Advanced Study in the Behavioral Sciences at Stanford University, California. The ethos is that, like "emotional intelligence", a set of human characteristics exists producing "future smart" individual and institutional actions. Future smart actions are concerned with the gap between our understanding of the threats to humanity and effective action. Why does society know so much about what is coming in the future, yet fails to act in ways that will result in a more equitable and sustainable future for all?

As such, the knowledge generated through MAHB is both theoretical and empirical, as well as connecting the two. Frameworks are being developed for determining how and why human behavior does and does not aim for sustainability, but then those frameworks are focused for on-the-ground analysis in specific locations and specific sectors. Other, specific practical studies which are ongoing to test and refine the theory include small island sustainability and energy use for transportation. 
2. Knowledge dissemination in scientific and popular science venues.

Generating new knowledge in the form of scientific publications is important, but MAHB's approach to knowledge supply does not stop with academic publishing. Videos are part of the outreach effort, such Ehrlich's efforts for academic audiences through the Jack Beales Lecture on the Global Environment (http://www. youtube.com/watch? $\mathrm{v}=\mathrm{YHc} 7-275 \mathrm{~h} 0 \mathrm{Y}$ ) and videos aimed at more general audiences such as radio interviews (http://www.youtube.com/watch?v=XGoG3fD7_ GQ) and clips on climate change (http://www.youtube.com/watch?v=HE4xsgz5uew).

Speaking about the potential collapse of global civilization and what could be done to avert it (Ehrlich and Ehrlich 2013) naturally draws media attention which helps to engage those beyond the scientific world, including non-Anglophone audiences (e.g. Foucart 2013). MAHB also runs an online library (http://mahb.stanford. edu/library/mahb-library) for members to share relevant material in any media. That covers scholarly work alongside children's books, popular media, and public lecture notes. The criterion for selecting library material is fact-based presentation of the sustainability challenges emphasizing solutions related to human behavior.

Using multimedia approaches does not preclude face-to-face contact. Several MAHB workshops have been organized, in locations including Stanford University, Gothenburg and Lund in Sweden, and Lisbon, focusing on fostering collaboration among social and natural scientists as well as humanists while engaging with concerned citizens, including those with policy- and decision-making power. Topics have including environmental modeling, governance, and risk analysis; sustainability in island communities; new forms of governance, especially when government is an inhibitor to sustainability processes; and business pathways to sustainability. In larger academic settings, MAHB members presented MAHB's work at conferences including the Ecological Society of America, the World Congress of Sociology, and the American Sociological Association.

Sustainability Summits in Oslo have also been a core venue for MAHB since 2007. The Sustainability Summits are designed to accomplish three purposes. First, to support the social sciences and humanities as global players regarding environment and sustainability topics. Second, to provide a platform engaging the greatest diversity of people to establish dialogue and mutual challenges among different sectors that often do not communicate. Social scientists, natural scientists, and humanists interact with non-scientists, including leaders of business, non-governmental organizations, and government-plus concerned citizens who attend. Third, to bring university students from around the world to formulate questions and to propose conceptualizations and strategies that are alternatives to those presented by the researchers and leaders at the summits. These "young challengers" collaborate to prepare their questions, arguments, and proposals, with the aim of positioning themselves as the new generation of leaders and researchers who will achieve a sustainable future.

3. Knowledge brokering, i.e. engaging non-scientists in sustainability-related action based on science.

Knowledge dissemination cannot just be one way, from the ostensible "expert" to the masses of the public. Instead, MAHB further serves as an intermediary 
matching up those seeking sustainability knowledge with those who have ideas and actions to offer. The key is bringing together scientists and non-scientists to provide desired science to those without a background to or in science, as well as to indicate to the scientists the form of knowledge which is requested in order to act.

As an example linked to the knowledge dissemination workshops mentioned above, in January 2013, MAHB hosted a meeting at Stanford University titled "Can Foresight Intelligence Prevent the Collapse of Civilization?" A diverse group met for a 2-day conversation on the psychological, economic, historical, sociological, and natural science dimensions of that question. The aim was to inspire discussion on all sectors acting against such a collapse.

Another example of MAHB's engagement beyond the scientific community is the work of Bob Horn from Stanford University who collaborated with the World Business Council for Sustainable Development to assess the business vision for a sustainable world in 2050 (WBCSD 2010). A major feature of this project is assessments of where we are now, with a significant component of assessing human behavior - of businesses, governments, non-governmental organizations, communities, and everyday citizens - with respect to sustainability. Strategists from more than two dozen companies went through an 18-month process of setting 350 milestones and 70 metrics for achieving a sustainable planet. They distilled these lists into 40 "must-haves" that would be essential to achieve the sustainability vision, indicating how each of the next four decades needs to look like to reach the 2050 goal. For example, for materials, during the 2010s, new legislation is needed to reduce dependence on landfills and to encourage reduction, reuse, and recycling. For agriculture in the 2030s, productivity in Brazil will need to be double the current levels while in Africa, it will need to have increased five-fold.

A major goal of MAHB is reaching out to its members to help those involved in social action to have access to understandable information for their work on sustainability. MAHB membership includes a substantial list of "concerned citizens", including those from business, religion, non-governmental organizations, youth groups, and home-makers of many socio-economic statuses. The key is to go beyond knowledge generation and dissemination towards knowledge-based action. MAHB's network and media offer opportunities for members to share ideas and experiences, with discussion and exploration of ideas being an important component but also ensuring that action results. To facilitate this, MAHB is developing a set of measurable impact goals which focus on working with scholars and concerned citizens to include the primary drivers of environmental degradation-namely inequality, population, and over-consumption by the wealthy - in their literature, public outreach, and activism.

To enact these activities of knowledge production, dissemination, and brokering, MAHB's basic structure is an informal, international network of social scientists, physical scientists, humanists, academics from professions, and other engaged scholars, alongside members of business, political, and civic communities. The openness ensures that anyone who joins the mission can do so on their own terms and contribute in the way in which they feel most comfortable. For that, MAHB uses various media: a website with blogging, a facebook group generating debates, seminars, and workshops-all with academic material as well as popular science content. As such, MAHB media and venues serve as meeting and interaction points between scientists and non-scientists. 
MAHB members can also create their own meeting and interaction points, to pursue MAHB's mission in their own location, by setting up a "node". The term "node" implies a connection point within a network or a vertex where several lines or vectors intersect in a large graph. MAHB's nodes are semi-autonomous groups to bring people together locally for pursuing the overarching MAHB goal. They draw on common MAHB information sources and goals to pursue actions locally pertinent to each node and each node's location.

MAHB nodes and partners exist across the globe. The first node was set up from 2007-2008 at Stanford University, California. The Stanford node focuses on a program of seminars and workshops designed to draw in researchers from across Stanford's academic strengths, such as energy engineering, climate change science, and environmental sociology.

\subsubsection{MAHB's Research Approach}

To understand pathways towards sustainability, MAHB specifically adopts an approach of use-inspired/problem-driven research that does not rely on a single discipline or single set of disciplines (e.g. see Clark 2007; NRC 1999). The research is use-inspired, because it aims at a practical application where policy-makers and decision-makers need the science and wish to use it for their policy and decisions. The research is problem-driven in that a practical problem is identified and research is used for tackling that problem, irrespective of the academic origins of the research approaches selected.

An example from MAHB is Hilary Schaffer Boudet's post-doctoral project at Stanford University. The U.S. Department of Energy is interested in how households decide to reduce their household energy use and so they funded a project to contribute toward solving this problem. Boudet and her team developed two curricula for children, based on the tenets of social cognitive theory (Bandura 1986), to teach the advantages and implementation of sustainable energy behavior. The curricula have been tested via a randomized controlled trial with 30 California Girl Scouts to determine their effectiveness in changing behavior. Thus far, results look promising.

Meanwhile, following on from WCED (1987), Burns and Witoszek (2012) outline a humanistic agenda for integrating humanist knowledge into global sustainability research. They provide a baseline for understanding the institutional and cultural barriers to accomplishing more sustainable processes within society. That is the problem driving the research. They also go further, suggesting several steps and strategies which can help to bring humanities concepts into, for instance, resource management in order to improve the economic, education, governance, and culture systems which favor unsustainable approaches. This work demonstrates that largescale societal transformations are one way of effecting behavioral change-as are less dramatic approaches such as viewing society as a learning system where a multitude of small actions can add up to a major difference (Burns 2012). 
Where a specific discipline can contribute to such research, its theories, literature, and methodologies are applied — and mixed with other disciplines to build on each discipline's strengths while shoring up any limitations. This research is not just for the pursuit of new knowledge, but is also about catalyzing and creating appropriate action based on the sound scientific knowledge produced. The focus of MAHB is not to displace other disciplines with social sciences and humanities inputs, nor is it to make social science and humanities inputs dominate. Instead, it is to ensure that all disciplinary voices, as well as inter-disciplinary voices, are heard and that they work together with mutual respect.

MAHB creates the space whereby such interaction can occur. By signing up to MAHB's mission, members accept the need for working with other disciplines. By attending a MAHB workshop, members accept that different disciplinary perspectives and approaches need to be respected, while also pushing themselves to think beyond specific disciplines. For example, at a MAHB workshop in Sweden in 2010 on risk, discussions ranged across different interpretations and understandings of risk in order to compare various disciplinary perspectives without becoming entrapped by one. One aim was to compile methods for influencing people's riskrelated behavior in order to inform risk reduction policy and practice.

The space created by MAHB for dialogue amongst all disciplines is furthermore about encouraging scientists to interact with policy and decision-makers. That means that policy- and decision-makers understand more about the scientific process. Meanwhile, scientists are encouraged to work with policy and decision-makers to produce science that can be used. Ehrlich, for instance, started his policyinfluencing career with The Population Bomb (Ehrlich and Ehrlich 1968) and continues to discuss the population-resource nexus with policy makers, highlighting that the sustainability challenges, according to him, are population, overconsumption, and inequality.

Ensuring this two-way exchange has various precedents, such as 'people's science' (Wisner et al. 1977) and 'useable science' (Glantz et al. 1990). Too often, science is seen as a linear process whereby knowledge is produced and then it might or might not be sent to policy- and decision-makers in a form which the policy and decision-makers might or might not be able to use. Among many others, Martin (1979) undercuts the myth of the objectivity of physical science results, using pollution and resource examples. One consequence is that environmental science cannot be assumed to stand alone from its policy and decision arena. MAHB therefore brings together the scientific and application arenas by focusing on a problem which parties wish to solve, recognizing that different skills and knowledge bases are needed to solve the problem and to use the results. That improves over many past endeavors, supporting better social science integration, because policy- and decision-makers are involved from the beginning-usually helping to define the problem to be solved-and by avoiding one discipline dominating others.

An example is Bob Horn's work with the World Business Council for Sustainable Development described earlier (WBCSD 2010). Because the business strategists were involved from the beginning and helped to define the problem to be tackled 
along with the tasks, they had an incentive to complete the work fully and then to consider how to apply the results for themselves. An added advantage is that the policy- and decision-makers involved gain an indication of the intricacies and uncertainties of scientific investigation, while educating scientists about the needs of the policy- and decision-makers.

The key area highlighted by MAHB for social science integration in the context of resource and sustainability challenges is showing how social science and humanities research draws attention to behavioral influences other than economic and technological considerations and framings. The latter often dominate discussions and assumptions regarding sustainability-related decisions, leading to the state of the world witnessed today. That does not denigrate the importance of material and economic interests, especially since they often operate in tandem with cultural and institutional factors. Indeed, the effectiveness of many economic incentives and technical innovations first requires major behavioral changes.

But moving beyond purely economic and technological considerations means recognizing that social sciences and humanities have much more to offer than understanding human behavior and perceptions to increase the uptake of advertised products (e.g. Mela et al. 1997) or indicating how people respond to economic incentives for risk reducing behavior (Kane et al. 2004). MAHB's framing and research approach treats the cause of the lack of sustainability (human behavior) rather than the symptoms (the physical indicators of resource depletion and environmental contamination). This does not denigrate or eliminate the past work or other framings. It builds on them, embraces them, and uses them as a springboard to understand more about the underlying drivers of poor sustainabilityrelated behavior.

One example of needed behavioral change is travelling less in order to save energy. For example, using e-based (e.g. skype) meetings, learning, and conferences tends to save money, is more environmentally friendly than travelling, and is becoming increasingly easier due to technological developments. It does, though, require users to accept that forum of interaction rather than the expectation of more personal face-to-face approaches.

Much of that acceptance or rejection is cultural and people have different levels of comfort for "Personal connections in the digital age" (the title of Baym 2010). Shea (2005) points out that informing and dealing with climate change in the Pacific islands requires "Establishing and sustaining 'eyeball-to-eyeball' contact" (p. 4). That is notwithstanding the PEACESAT operation which, for over three decades while based in Honolulu, has used remote education through video and then the internet for training and education on development and sustainability topics, including climate change adaptation and resource management. No studies have yet examined the elements of PEACESAT which build up long-distance trust and credibility, compared to the cultural desire for the "eyeball-to-eyeball" contact. Understanding these dimensions of human behavior with respect to sustainability would be a research and application project directly in line with MAHB's aims and approach. 


\subsection{A Research Agenda for and from MAHB}

Ehrlich and Kennedy (2005, p. 563) earlier defined a five-point research agenda for MAHB to highlight social sciences and humanities integrating with physical sciences:

(i) what social scientists and others know about mechanisms of cultural evolution and how changes in direction might be steered democratically; (ii) how scarce and unevenly distributed non-renewable resources are used and some of the ethical connections between distribution, economic opportunity, and access; (iii) ethical issues related to the world trade system; (iv) conflicts between individual reproductive desires and environmental goals; and (v) economic, racial, and gender inequity as contributors to environmental deterioration.

This section specifies expanded research questions for MAHB within reconfigured categories, as future opportunities for social science integration for resource management and sustainability.

\subsubsection{Socio-cultural Change for Sustainability}

Behavioral factors for socio-cultural change are frequently missed from technical perspectives of meeting sustainability challenges. In particular, for problems such as resource management, technical solutions are often imposed without considering how the problem might be overcome through behavior or how the solution itself might unintentionally alter behavior (e.g. Wilde 1994). By integrating social science and the humanities into physical sciences and policy processes, the risk of unintended consequences is diminished and policy making is likely to be more effective.

For example, in speaking with people owning hybrid cars, the authors have noticed a tendency for the owners to assume that driving is not a problem because their car is a hybrid. In fact, they often drive more than before. A useful solution to reduce fossil fuel consumption exists, through hybrid cars, leading to increased driving which counteracts some of the gain while increasing congestion and the need for road maintenance. Further investigation of two key classes of behavioral factors in conjunction with the technical solutions could assist in overcoming such challenges.

The first class is socio-cultural mechanisms of re-framing, re-definition, and other cognitive shifts so that problems are seen from new perspectives and new solutions are envisioned. That includes developing new narratives and discourses which play a major role in many cognitive shifts. One classic baseline is 'paradigm shifts' (Kuhn 1962), a concept which has been critiqued (Toulmin 1972) with the debate raging ever since, but nonetheless applied to public policy paradigm shifts (e.g. Carson et al. 2009). As is usual, reality seems to display both sudden and evolutionary changes in ideas, thoughts, and actions. Much more work is needed to understand the traits of changes at different time scales and how the time scale of 
behavioral change could be influenced. For example, some attribute a sudden change in U.S. forest management towards wildfire suppression as a result of the movie Bambi (Nash 1985). That compares to a later, much more gradual shift towards different regimes of managed burns (North et al. 2012).

The second class of key behavioral factors is understanding the main players who influence behavioral change with respect to policy and institutional shifts. The categories players which are particularly underrepresented in studies are:

(a) Social movements, because they raise awareness and play critical roles in cognitive changes and the development of new identities (Carson et al. 2009). Examples are "Corporate (Social) Responsibility" and "Green Citizens".

(b) Institutions exercising social power which may facilitate or constrain sustainability-related behavior. Advertising plays a key role. An example is airlines and car companies using environmental imagery and identities to sell their products. Another example is brandjacking, such as an environmental organization hijacking a corporate brand as epitomized by Greenpeace mocking Shell's "Arctic Ready" campaign (http://arcticready.com).

(c) Specific champions or icons, individual and organizational, in promoting a new sustainability ethos and new sustainability practices. Performing artists and sports stars often play key roles. United Nations agencies, for instance, use celebrities as Goodwill Ambassadors and Special Envoys. Midttun (2013) highlights the role of "cultural educators and protagonists" in developing a sustainability ethos and sustainability practices.

Within socio-cultural change for sustainability, several MAHB members have embarked on a study of island communities. Many island communities seek sociocultural change because they are now highly vulnerable to the forms of social and environmental disasters which will be expected to affect most of humanity in the future, unless sustainable pathways are chosen. This research focuses on innovative responses, particularly to climate change challenges, from technical, economic, governance, and cultural perspectives. For example, innovation in energy technologies and policies, which often need to be self-sufficient for isolated island communities, are described by Baumgartner and Burns (1984) and Woodward et al. (1994). A related research program involving MAHB partners identifies ways in which human agents (individuals and collectives) bring about technical, economic, governance, and cultural innovation in response to climate change through case studies of cultures and institutions in Scandinavia, China, and Ghana (Midttun 2009).

\subsubsection{Population and Sustainability}

Malthusian and neo-Malthusian debates focusing on population numbers permeate sustainability research, policy, and practice. Few claim that population numbers are the only factor causing resource problems, just as few claim that population numbers are irrelevant for analyzing and solving resource problems. Reality is persistently 
complicated, as shown by relationships between population size and carbon dioxide emissions (Jorgenson and Clark 2013) and between population density and agro-diversity (Conelly and Chaiken 2000).

As such, MAHB's research agenda for population and sustainability embraces parameters such as population numbers, population densities, consumption rates, waste rates, affluence, and technology. Analyzing these various factors and the circumstances under which they contribute more to a specific resource problem, or less, is MAHB's research agenda.

For example, a small island such as Malé, the capital of the Maldives, is $100 \%$ urbanized. Building further high-rises is not straightforward because the island's land, effectively at sea-level, has the potential of sinking with such added weight. There is an upper limit to how many people can live on the island without land reclamation. Conversely, the suburbs of Los Angeles are a clear example of urban sprawl in which long, wide streets and large plots for big houses epitomize high resource consumption per capita. What are the behavioral factors drawing different classes of people to these different urban environments? How could behavior be influenced to reduce population density in Malé and to reduce resource consumption in Los Angeles? Both locations display a combination of technical and social challenges. Neither can be solved without the social sciences and the humanities and neither can be solved with only the social sciences and the humanities. Instead, a combination of disciplines working in tandem to solve the place-specific problem is needed, exactly in line with MAHB's ethos.

Another layer can be added to these questions: How can researchers, policy makers, and practitioners focus on the fundamental population-related factors based on science? When population numbers are raised as a specter, the debate often leads to accusations of advocating reproductive control, perhaps through forced sterilization or forced abortion. Such unethical measures are supported by only an extremist minority, yet they often dominate the debate. That is the case even though social science provides details on how raising people's education and affluence levels, especially in terms of giving women reproductive-related education and choices, tends to lead to smaller families, higher infant survival, and better educated children (e.g. Martin 1995). Solving the challenge within MAHB's work is two-fold: Ensuring that scientific arguments dominate debates and keeping the discussion on the fundamental factors rather than having to defend against extremist arguments.

\subsubsection{Environmental Governance for Sustainability}

MAHB researchers have been contributing to bringing social sciences and the humanities into environmental governance regimes-including the governance of risk and using democratic change to achieve sustainability processes. Midttun (2010) edited a special issue of Corporate Governance, called "Rethinking Governance for Sustainability". Carson et al. (2009) investigated public policy 
paradigm shifts in the EU's management of asbestos, chemicals, climate change, and gas markets. Other resource-related studies from MAHB on environmental governance for sustainability include Baltic fisheries (Burns and Stohr 2011) and tropical forests (Nikoloyuk et al. 2010).

This governance research has been identifying and analyzing a variety of mechanisms of "soft means" for advancing public policy. "Soft means" stress noneconomic and non-coercive incentives and pressures. Of particular interest for further investigation are how issues are framed politically (such as defining a policy issue as "European"); how data are selected, collected, and distributed; standardization of measurements and classification schemes; monitoring of opinion and behavior; and support for forming informed opinions and mutual learning processes. This wide variety of means shows that, even though managing resources such as forests and fish might have traditionally been seen as pursuits in ecology or biology, integrating social science (e.g. governance, individual attitudes, and education) is needed to achieve effective public policy and action.

\subsubsection{Inequity and Sustainability}

When determining how to use and misuse resources, many discussions within sustainability refer to resource distribution, access, and choices. People's individual and collective behavior is often attributed to political ideology, whether it be the approach epitomized by the legend (and likely reality) of Robin Hood, through stealing from the rich in order to give to the poor, or through modern-day unchecked capitalism, often interpreted as being as much short-term profit as feasible. Yet empirical evidence suggests that the links between values or ideology and behavior are rarely linear or straightforward (Osbaldiston and Schott 2012; Schultz et al. 2005).

MAHB aims to contribute to research on this topic by trying to understand more about how and why inequalities are created and perpetuated for resource distribution, access, and choices. "Selfishness", "greed", "ignorance", or "egoism" are answers which are too simplistic in themselves, because these characteristics, amongst many others, tend to be present to different degrees.

For instance, in terms of ignorance, commendable efforts to tackle deforestation in less affluent countries, such as by celebrities including Harrison Ford (http:// www.youtube.com/watch? $v=r 87 \mathrm{wJ} 1 \mathrm{QmyY}$ w), do not necessarily acknowledge that the deforestation is driven primarily by large-scale agriculture for markets in more affluent countries (Butler and Laurance 2008). That is, affluent consumers desire products which are cheap to produce through rain forest destruction. The affluent consumers then blame those working on the land which used to be rain forest. Those with the power and resources to change are blaming those without the power and resources to change for sustainability problems.

How could such inequalities of power and perception be overcome? Does the disparity between the thoughts and actions of the affluent consumers emerge from 
ignorance, greed, or other characteristics? Could consumer behavior be changed to reduce inequalities even if product costs increase (although life-cycle costs might decrease due to less environmental destruction)? These are questions on MAHB's research agenda regarding inequality and sustainability.

This topic connects back to topic (1) in terms of socio-cultural mechanisms of re-framing, re-definition, and other cognitive shifts. Ethical and value systems play an important role, which influence and are influenced by political ideology. That requires further work into how ethical systems such as "do no harm", "risk/benefit analysis", and "utilitarianism" view inequalities and overcoming inequalities both theoretically and operationally. Some also differentiate between equity, equality, and egalitarianism (e.g. Espinoza 2007). None of that addresses the fundamental challenge with respect to inequalities and sustainability: understanding and overcoming the disconnect between beliefs and actions so that certain sectors or institutions do not hoard or dominate control of available (and always constrained) resources (including information and knowledge).

In fact, one common thread through the above themes is that simple conceptual models of influencing behavior, and of understanding the root impetus of action, rarely manifest in reality, even when they appear in the literature. The reason is that these simple models are usually for highly specific cases in highly specific contexts, often with many variables controlled for the study which could not be controlled in reality. For instance, one model of behavioral change applies ABC referring to first influence Attitude which affects Behavior leading to the Change sought (Kumar 1996). Empirical evidence is not always supportive of the ABC sequence for sustainability behavior. Ample studies indicate that, even when people have an appropriate attitude, such as wishing to be environmentally friendly, and even when they identify the appropriate behavior, such as flying less to save fossil fuels, they do not always change in order to implement what they know (McKercher et al. 2010). Environmental scientists are a poignant example (Stohl 2008).

Whether with respect to socio-cultural change, ethics, population, or inequity, the fundamental objective within MAHB's research is to determine the underlying motivations to sustainability decision-making leading to successful action, rather than just attitudes and behavioral awareness. Part of that is drilling deeper than the simpler models which often do not work in practice, such as ABC. In particular, differentiating and conceptualizing values, attitudes, knowledge, and behavior is often poorly effected in studies. Overall, there is a dearth of research in determining how and why information and knowledge are and are not converted into behavioral changes and action.

The current status of integrating social science into understanding sustainability behavior has not yet fully described the links amongst values, attitudes, and knowledge — or how those lead to influencing behavior and action. MAHB, amongst other initiatives, contributes to engaging all science and other knowledge forms to build on and support ongoing work and to more fully engage everyone in addressing the challenges to the planet and humanity. 


\subsection{Concluding Reflections}

1. MAHB is part of a global development which is forging links among researchers in the physical sciences, social sciences, and humanities-as well as with non-scientists.

2. MAHB stresses the necessity of behaviorally-focused approaches to achieving sustainability processes. One challenge is to identify and develop the kind of social science and humanities information, knowledge, and wisdom which could play a useful, even if not decisive, role in policy- and decision-making. Areas which social scientists have shown to be important include: (a) cognitive and framing concepts; (b) social networks; (c) social movements; (d) social power; (e) social change and evolution; and (f) methods and theoretical frameworks encompassing systems analysis, social ecology, human interaction and agency.

3. In spite of considerable progress in science, it seems that policy and strategy development for sustainable resource management is not informed enough by or through the social sciences and humanities. Social scientists and humanists need to learn from physical scientists who have become increasingly skillful in reformulating scientific knowledge into everyday language and communicating with concerned citizens who seek such knowledge.

4. The social sciences and humanities may identify policy openings and unseen opportunities as well as policy and institutional barriers.

5. All in all, the social sciences and the humanities have had rich and productive histories providing a substantial scholarly base upon which to draw for sustainable resource management. Integrating that knowledge means systematically applying it for encouraging behavior that will support sustainability processes.

MAHB is a unique initiative, establishing a permanent arena for dialogue and collaboration amongst all scientists, humanists, and non-scientists in the context of public policy engagement and outreach.

Open Access This chapter is distributed under the terms of the Creative Commons Attribution Noncommercial License, which permits any noncommercial use, distribution, and reproduction in any medium, provided the original author(s) and source are credited.

\section{References}

Bandura, A. (1986). Social foundations of thought and action. Englewood Cliffs: Prentice-Hall.

Barry, J., \& Quilley, S. (2009). The transition to sustainability: Transition towns and sustainable communities. In L. Leonard \& J. Barry (Eds.), The transition to sustainable living and practice (pp. 1-28). Bingley: Emerald.

Bartlett, A. A. (2004). The essential exponential! Lincoln: University of Nebraska.

Baumgarter, T., \& Burns, R. R. (1984). Transitions to alternative energy systems: Entrepreneurs, new technologies, and social change. Boulder: Westview Press. 
Baym, N. K. (2010). Personal connections in the digital age. Cambridge: Polity.

Boyle, J. R., Warila, J. E., Beschta, R. L., Reiter, M., Chambers, C. C., Gibson, W. P., Gregory, S. V., Grizzel, J., Hagar, J. C., Li, J. L., Mccomb, W. C., Parzybok, T. W., \& Taylor, G. (1997). Cumulative effects of forestry practices: An example framework for evaluation from Oregon, U.S.A. Biomass and Bioenergy, 13(4-5), 223-245.

Brown, B. J., Hanson, M. E., Liverman, D. M., \& Merideth, R. W. (1987). Global sustainability: Toward definition. Environmental Management, 11(6), 713-719.

Bryan, J., Shearman, P., Ash, J., \& Kirkpatrick, J. B. (2010). Estimating rainforest biomass stocks and carbon loss from deforestation and degradation in Papua New Guinea 1972-2002: Best estimates, uncertainties and research needs. Journal of Environmental Management, 91(4), 995-1001.

Burns, T. R. (2012). The sustainability revolution: A societal paradigm shift? Sustainability, 4(6), $1118-1134$.

Burns, T. R., \& Stohr, C. (2011). Power, knowledge, and conflict in the shaping of commons governance. The case of EU Baltic fisheries. International Journal of the Commons, 5(2), 233-258.

Burns, T. R., \& Witoszek, N. (2012). Sustainability: A humanistic agenda. Journal of Human Ecology, 39(2), 155-170.

Butler, R. A., \& Laurance, W. F. (2008). New strategies for conserving tropical forests. Trends in Ecology \& Evolution, 23(9), 469-472.

Carson, M., Burns, T. R., \& Calvo, D. (2009). Public policy paradigms: Theory and practice of paradigm shifts in the European Union. Frankfurt/New York/Oxford: Peter Lang.

Clark, W. C. (2007). Sustainability science: A room of its own. Proceedings of the National Academy of Sciences, 104(6), 1737-1738.

Conelly, W. T., \& Chaiken, M. S. (2000). Intensive farming, agro-diversity, and food security under conditions of extreme population pressure in Western Kenya. Human Ecology, 28(1), 19-51.

Dessler, A. E. (2010). A determination of the cloud feedback from climate variations over the past decade. Science, 330(6010), 1523-1527.

Downie, D. L., \& Fenge, T. (Eds.). (2003). Northern lights against POPs: Combating threats in the Arctic. Montreal: McGill-Queen's University Press.

Eckhardt, S., Stohl, A., Beirle, S., Spichtinger, N., James, P., Forster, C., Junker, C., Wagner, T., Platt, U., \& Jennings, S. G. (2003). The North Atlantic oscillation controls air pollution transport to the Arctic. Atmospheric Chemistry and Physics, 3(5), 1769-1778.

Ehrlich, P. R., \& (uncredited) Ehrlich, A. (1968). The population bomb. New York: Sierra Club/ Ballantine Books.

Ehrlich, P. R., \& Ehrlich, A. H. (2012). Solving the human predicament. International Journal of Environmental Studies, 69(4), 557-565.

Ehrlich, P. R., \& Ehrlich, A. H. (2013). Can a collapse of civilization be avoided? Proceedings of the Royal Society B, 280(1754), 20122501. doi:10.1098/rspb.2012.2501.

Ehrlich, P. R., \& Kennedy, D. (2005). Millennium assessment of human behavior. Science, 309, 562-563.

Ehrlich, P. R., Kareiva, P. M., \& Daily, G. C. (2012). Securing natural capital and expanding equity to rescale civilization. Nature, 486, 68-73.

Espinoza, O. (2007). Solving the equity-equality conceptual dilemma: A new model for analysis of the educational process. Educational Research, 49(4), 343-363.

Flint, C., \& Brennan, M. (2006). Community emergency response teams: From disaster responders to community builders. Rural Realities, 1(3), 1-9.

Foucart, S. (2013, February 9). Notre civilization pourrait-elle s'effondrer? Personne ne veut y croire. Le Monde, Culture \& Idées, p. 4.

Gatto, M. (1995). Sustainability: Is it a well defined concept? Ecological Applications, 5(4), 1181-1183.

Glantz, M. H., Price, M. F., \& Krenz, M. E. (1990). Report of the workshop "On assessing winners and losers in the context of global warming, St. Julians, Malta, 18-21 June 1990". Boulder: Environmental and Social Impacts Group, National Center for Atmospheric Research. 
IPCC. (2007). IPCC fourth assessment report. Geneva: Intergovernmental Panel on Climate Change.

Jerneck, A., \& Olsson, L. (2014). Food first! Theorising assets and actors in agroforestry: Risk evaders, opportunity seekers and 'the food imperative' in sub-Saharan Africa. International Journal of Agricultural Sustainability, 12(1), 1-22.

Jorgenson, A. K., \& Clark, B. (2013). The relationship between national-level carbon dioxide emissions and population size: An assessment of regional and temporal variation, 1960-2005. PLoS ONE, 8(2), e57107. doi:10.1371/journal.pone.0057107.

Kane, R. L., Johnson, P. E., Town, R. J., \& Butler, M. (2004). A structured review of the effect of economic incentives on consumers' preventive behavior. American Journal of Preventive Medicine, 27(4), 327-352.

Kelman, I. (2008). Relocalising disaster risk reduction for urban resilience. Urban Design and Planning, 161(DP4), 197-204.

Klare, M. T. (2012). The race for what's left: The global scramble for the world's last resources. New York: Metropolitan Books.

Knutson, T. R., McBride, J. L., Chan, J., Emanuel, K., Holland, G., Landsea, C., Held, I., Kossin, J. P., Srivastava, A. K., \& Sugi, M. (2010). Tropical cyclones and climate change. Nature Geoscience, 3, 157-163.

Kuhn, T. (1962). The structure of scientific revolutions. Chicago: Chicago University Press.

Kumar, S. (1996). ABC of PRA: Attitude and behaviour change. PLA Notes: Participation, Policy and Institutionalisation, 27, 70-73.

Martin, B. (1979). The bias of science. Canberra: Society for Social Responsibility in Science.

Martin, T. C. (1995). Women's education and fertility: Results from 26 demographic and health surveys. Studies in Family Planning, 26(4), 187-202.

McKercher, B., Prideaux, B., Cheung, C., \& Law, R. (2010). Achieving voluntary reductions in the carbon footprint of tourism and climate change. Journal of Sustainable Tourism, 18(3), 297-317.

MEA. (2005). Millennium ecosystem assessment, ecosystems and human well-being. Washington, DC: Island Press.

Mela, C. F., Gupta, S., \& Lehmann, D. R. (1997). The long-term impact of promotion and advertising on consumer brand choice. Journal of Marketing Research, 34(2), 248-261.

Midttun, A. (Ed.). (2009). Stakeholders on climate change. North and South perspectives (Report No. 3). Oslo: CERES21-Creative Responses to Sustainability.

Midttun, A. (2010). Rethinking governance for sustainability. Corporate Governance, 10(1), 6-109.

Midttun, A. (2013). The anatomy of green transition. London: Palgrave Macmillan.

Mitchell, R. B., Clark, W. C., Cash, D. W., \& Dickson, N. M. (2006). Global environmental assessments: Information and influence. Cambridge, MA: MIT Press.

Nash, R. (1985). Sorry, Bambi, but man must enter the forest: Perspectives on the old wilderness and the new". Section 7, "Banquet Address". In J. E. Lotan, B. M. Kilgore, W. C. Fischer, \& R.W. Mutch (Technical coordinators), Proceedings-Symposium and workshop on wilderness fire, 1983 November 15-18, Missoula MT (pp. 264-268). General Technical Report INT-182 from U.S. Department of Agriculture, Forest Service, Intermountain Forest and Range Experiment Station.

Nikoloyuk, J., Burns, T. R., \& de Man, R. (2010). The promise and limitations of partnered governance: The case of sustainable palm oil. Corporate Governance, 10(1), 59-72.

North, M., Collins, B. M., \& Scott, S. (2012). Using fire to increase the scale, benefits, and future maintenance of fuels treatments. Journal of Forestry, 110(7), 392-401.

NRC. (1999). Our common journey: A transition towards sustainability. Washington, DC: National Academy Press.

Osbaldiston, R., \& Schott, J. P. (2012). Environmental sustainability and behavioral science metaanalysis of pro-environmental behavior experiments. Environment and Behavior, 44(2), 257-299. 
Rees, W. E. (2006). Ecological footprints and biocapacity: Essential elements in sustainability assessment. In J. Dewulf \& H. V. Langenhove (Eds.), Renewables-based technology: Sustainability assessment (pp. 143-157). Chichester: John Wiley \& Sons.

Rees, W. E. (2013). Ecological footprint, concept of. In S. Levin (Ed.), Encyclopedia of biodiversity (2nd ed.). San Diego: Academic.

Reis, S., Grennfelt, P., Klimont, Z., Amann, M., ApSimon, H., Hettelingh, J.-P., Holland, M., LeGall, A.-C., Maas, R., Posch, M., Spranger, T., Sutton, M. A., \& Williams, M. (2012). From acid rain to climate change. Science, 338(6111), 1153-1154.

Reynolds, R. (2008). On guerrilla gardening: A handbook for gardening without boundaries. London: Bloomsbury.

Rosa, E. A., Kennedy, D., Ehrlich, P., Burns, T. R., Kelman, I., Midttun, A., \& Witoszek, N. (2011). The millennium assessment of human behavior-5+ years later. Mother Pelican: A Journal of Sustainable Human Development, 7(8), 2.

Santillo, D. (2007). Reclaiming the definition of sustainability. Environmental Science and Pollution Research, 14(1), 60-66.

Schultz, P. W., Gouveia, V. V., Cameron, L. D., Tankha, G., Schmuck, P., \& Franěk, M. (2005). Values and their relationship to environmental concern and conservation behavior. Journal of Cross-Cultural Psychology, 36(4), 457-475.

Seaton, A., MacNee, W., Donaldson, K., \& Godden, D. (1995). Particulate air pollution and acute health effects. The Lancet, 345, 176-178.

Shea, E. (2005, January 9-13). Living with a climate in transition: Pacific Islands experience. Paper 14.3 at the 16th conference on climate variability and change, San Diego, CA, USA.

Stohl, A. (2008). The travel-related carbon dioxide emissions of atmospheric researchers. Atmospheric Chemistry and Physics, 8, 6499-6504.

Tainter, J. A. (1988). The collapse of complex societies. Cambridge: Cambridge University Press.

Thomas, V. M., Socolow, R. H., Fanelli, J. J., \& Spir, T. G. (1999). Effects of reducing lead in gasoline: An analysis of the international experience. Environmental Science and Technology, 33(22), 3942-3948.

Toulmin, S. (1972). Human understanding: The collective use and evolution of concepts. Princeton: Princeton University Press.

Vandenberg, L. N., Colborn, T., Hayes, T. B., Heindel, J. J., Jacobs, D. R., Jr., Lee, D. H., Shioda, T., Soto, A. M., Vom Saal, F. S., Welshons, W. V., Zoeller, R. T., \& Myers, J. P. (2012). Hormones and endocrine-disrupting chemicals: Low-dose effects and nonmonotonic dose responses. Endocrine Reviews, 33(3), 378-455.

Velders, G. J. M., Fahey, D. W., Daniel, J. S., McFarland, M., \& Andersen, S. O. (2009). The large contribution of projected HFC emissions to future climate forcing. Proceedings of the National Academy of Sciences, 106(27), 10949-10954.

WBCSD. (2010). Vision 2050: The new agenda for business. Geneva: WBCSD.

WCED (World Commission on Environment and Development). (1987). Our common future. Oxford: Oxford University Press.

Wilde, G. J. S. (1994). Target risk. Toronto: PDE Publications.

Wisner, B., O'Keefe, P., \& Westgate, K. (1977). Global systems and local disasters: the untapped power of people's science. Disasters, 1(1), 47-57.

Woodward, A., Ellig, J., \& Burns, T. R. (1994). Municipal entrepreneurship and energy policy: A five nation study of politics, innovation, and social change. New York: Gordon and Breach.

Zhang, M., Song, Y., \& Cai, X. (2007). A health-based assessment of particulate air pollution in urban areas of Beijing in 2000-2004. Science of the total environment, 376(1-3), 100-108.

Zhang, X., Jiang, H., Jin, J., Xu, X., \& Zhang, Q. (2012). Analysis of acid rain patterns in northeastern China using a decision tree method. Atmospheric Environment, 46, 590-596. 